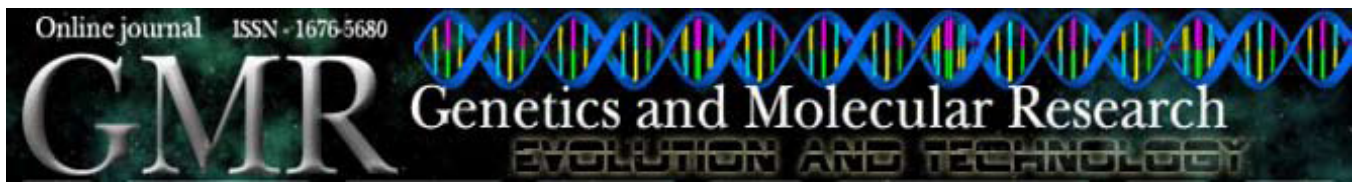

\title{
Characterization of the complete mitochondrial genome of the Rock pigeon, Columba livia (Columbiformes: Columbidae)
}

\author{
X.Z. Kan, X.F. Li, L.Q. Zhang, L. Chen, C.J. Qian, X.W. Zhang and L. Wang \\ The Provincial Key Laboratory of the Conservation and Exploitation Research \\ of Biological Resources in Anhui, College of Life Sciences, \\ Anhui Normal University, Wuhu, China \\ Corresponding author: X.Z. Kan \\ E-mail: xianzhaokan@gmail.com
}

Genet. Mol. Res. 9 (2): 1234-1249 (2010)

Received March 4, 2010

Accepted April 3, 2010

Published June 29, 2010

DOI 10.4238/vol9-2gmr853

\begin{abstract}
The rock pigeon (Columba livia), or Rock dove, is a member of the bird family Columbidae. We mapped the complete mitochondrial genome of the Rock pigeon. The mitochondrial genome of this species is a circular molecule of 17,229 bp in length, encoding a standard set of 13 protein-coding genes, two ribosomal RNA genes, and 22 transfer RNA genes, plus a putative control region, demonstrating a structure very similar to that of other birds. As found in other vertebrates, most of these genes are coded on the H-strand, except for NADH dehydrogenase subunit 6 (nad6) and eight tRNA genes (Gln, Ala, Asn, Cys, Tyr, Ser(UCN), Pro, Glu). The AT skew and GC skew of the whole genome, protein-coding genes, tRNA, rRNA, and the control region were calculated for the complete mitochondrial genomes of 30 avian species, representing 29 orders. All protein-coding genes initiated with ATG, except for coxl and nad5, which began with GTG. One extra nucleotide ' $\mathrm{C}$ ' was present in NADH dehydrogenase subunit 3 (nad3). All tRNA gene sequences have the potential to fold into typical
\end{abstract}


cloverleaf secondary structures. Within the control region, conserved sequences were identified in three domains. Although the conserved blocks, such as ETAS1, ETAS2, CSB1, CSB1-like, and boxes C, D, $\mathrm{E}$, and $\mathrm{F}$, are readily identifiable in the $C$. livia control region, the typical origin of $\mathrm{H}$-strand replication $\left(\mathrm{O}_{\mathrm{H}}\right), \mathrm{CSB} 2$ and CSB3 could not be detected. These results provide basic information for phylogenetic analyses of birds, especially Columbiformes species.

Key words: Mitochondrial genome; Rock pigeon; Columba livia; Columbiformes

\section{INTRODUCTION}

There are around 10,000 living species of birds, making them the most numerous tetrapod vertebrates. All modern birds are classified within the subclass Neornithes, which has two subdivisions: the Palaeognathae, containing mostly flightless birds, like ostriches, and the very diverse Neognathae, containing all other birds (Livezey and Zusi, 2007). Columbiformes is one of the most easily recognized avian orders worldwide and is traditionally subdivided into two families, the Columbidae and the Raphidae (Pereira et al., 2007). The Columbidae currently include over 300 species of pigeons and doves. The Rock pigeon (Columba livia), or Rock dove, is a member of the family Columbidae. This species includes the domestic pigeon, the feral pigeon, and the wild Rock pigeon. Wild Rock pigeons are pale grey, with two black bars on each wing; although domestic and feral pigeons are very variable in color and pattern. The Rock pigeon has a restricted natural resident range in western and southern Europe, north Africa, and south Asia. This species has been domesticated for several thousand years, giving rise to the domestic pigeon. Many domestic birds have escaped or have been released over the years, and have given rise to the feral pigeon. Feral pigeons are found in large numbers in cities and towns all over the world.

Genome-scale approaches have played an important role in the inference of evolutionary relationships among diverse organisms (Rokas et al., 2003). Compared with the nuclear genome, the mitochondrial genome has several intrinsic characteristics (small genome size, fast substitution rate and maternal inheritance mode), which render the mitogenome as one of the most suitable markers for phylogenetic (Wang et al., 2008) and population genetics studies, such as analysis of gene flow, hybridization and introgression (Moore, 1995).

Typical metazoan mitochondrial genomes are double-stranded circular molecules, ranging in size from approximately 15 to $20 \mathrm{~kb}$ and containing 37 genes: 13 protein-coding genes, 22 transfer RNA genes (tRNAs) and two ribosomal RNA genes (rRNAs) (Boore, 1999). Additionally, one major control region is believed to control the initiation of replication and transcription of animal mitochondrial DNA (mtDNA) (Shadel and Clayton, 1997). To date, nearly 110 complete mtDNA sequences are available for 28 avian species (Table 1); however, no complete mitochondrial sequence has been published for members of the order Columbiformes, except for one sequence deposited in GenBank (NC_013244). Here, we present the complete mitochondrial genome of the Rock pigeon, C. livia (Columbiformes: Columbidae) and give a thorough description of its genome features in comparison to other avian species. 
Table 1. List of avian species examined in this study, classified according to Howard and Moore (2003).

\begin{tabular}{|c|c|c|c|c|}
\hline Order & Family & Species & Accession No. & Reference \\
\hline \multicolumn{5}{|l|}{ Neognathae } \\
\hline Anseriformes & Anatidae & Branta canadensis & NC_007011 & Unpublished data ${ }^{\mathrm{a}}$ \\
\hline Apodiformes & Apodidae & Apus apus & NC_008540 & Unpublished data $^{\mathrm{b}}$ \\
\hline Caprimulgiformes & Aegothelidae & Aegotheles cristatus & NC_011718 & (Pratt et al., 2009) \\
\hline Charadriiformes & Haematopodidae & Haematopus ater & NC_003713 & (Paton et al., 2002) \\
\hline Ciconiiformes & Ciconiidae & Ciconia ciconia & NC_002197 & Unpublished data $^{c}$ \\
\hline Columbiformes & Columbidae & Hemiphaga novaeseelandiae & NC_013244 & Unpublished data $^{\mathrm{d}}$ \\
\hline Coraciiformes & Coraciidae & Eurystomus orientalis & NC_011716 & (Pratt et al., 2009) \\
\hline Cuculiformes & Neomorphidae & Geococcyx californianus & NC_011711 & (Pratt et al., 2009) \\
\hline Falconiformes & Falconidae & Falco peregrinus & NC_000878 & (Mindell et al., 1998) \\
\hline Galliformes & Phasianidae & Gallus gallus & NC_007236 & (Nishibori et al., 2005) \\
\hline Gaviiformes & Gaviidae & Gavia stellata & NC_007007 & (Slack et al., 2006) \\
\hline Gruiformes & Rhynochetidae & Rhynochetos jubatus & NC_010091 & (Morgan-Richards et al., 2008) \\
\hline Passeriformes & Menuridae & Menura novaehollandiae & NC_007883 & (Slack et al., 2007) \\
\hline Pelecaniformes & Phaethontidae & Phaethon rubricauda & NC_007979 & Unpublished data ${ }^{\mathrm{e}}$ \\
\hline Phoenicopteriformes & Phoenicopteridae & Phoenicopterus ruber & NC_010089 & (Morgan-Richards et al., 2008) \\
\hline Piciformes & Ramphastidae & Pteroglossus azara & NC_008549 & (Gibb et al., 2007) \\
\hline Podicipediformes & Podicipedidae & Tachybaptus novaehollandiae & NC_010095 & (Morgan-Richards et al., 2008) \\
\hline Procellariiformes & Diomedeidae & Thalassarche melanophrys & NC_007172 & (Slack et al., 2006) \\
\hline Psittaciformes & Psittacidae & Melopsittacus undulatus & NC_009134 & Unpublished data $^{\mathrm{f}}$ \\
\hline Rheiformes & Rheidae & Rhea americana & NC_000846 & (Harlid et al., 1998) \\
\hline Sphenisciformes & Spheniscidae & Eudyptula minor & NC_004538 & (Slack et al., 2003) \\
\hline Strigiformes & Strigidae & Ninox novaeseelandiae & NC_005932 & (Harrison et al., 2004) \\
\hline Struthioniformes & Struthionidae & Struthio camelus & NC_002785 & (Haddrath and Baker, 2001) \\
\hline Tinamiformes & Tinamidae & Tinamus major & NC_002781 & (Haddrath and Baker, 2001) \\
\hline Trochiliformes & Trochilidae & Archilochus colubris & NC_010094 & (Morgan-Richards et al., 2008) \\
\hline Trogoniformes & Trogonidae & Trogon viridis & NC_011714 & (Pratt et al., 2009) \\
\hline \multicolumn{5}{|l|}{ Palaeognathae } \\
\hline Apterygiformes & Apterygidae & Apteryx haastii & NC_002782 & (Haddrath and Baker, 2001) \\
\hline Casuariiformes & Casuariidae & Casuarius casuarius & NC_002778 & (Haddrath and Baker, 2001) \\
\hline Dinornithiformes & Dinornithidae & Dinornis giganteus & NC_002672 & (Cooper et al., 2001) \\
\hline
\end{tabular}

\section{MATERIAL AND METHODS}

\section{Sample collection and DNA extraction}

An adult domestic male Rock pigeon was collected in Wuhu, Anhui Province, China. Total genomic DNA was extracted from the muscle tissue using standard phenol/chloroform methods (Sambrook and Russell, 2001).

\section{PCR amplification and sequencing}

Natural transfer of DNA from the mitochondria to the nucleus generates nuclear copies of mtDNA (NUMTs) and is an ongoing evolutionary process (Hazkani-Covo et al., 2010). To minimize the possibility of obtaining NUMTs, two long overlapping fragments 
( $\sim 12 \mathrm{~kb}$ in length) were first amplified using the long and accurate-polymerase chain reaction (LA-PCR) kit (Takara, Dalian, China). The first LA-PCR primer set was LA16SF (5'-CCTACGTGATCTGAGTTCAGACCGGAGCAATCCAG-3') of Nishibori et al. (2001) and CytbR252 (5'-GATGCAGATGAAGAAGAATGAGGCGCCGTTTGC-3') designed based on the sequence of the cytochrome b gene ( $c o b$ ) from Cabot's tragopan. The second primer set was LACLMTF (5'-GAAGCATCATCTCCCACCTAGAATGAAAATTC-3') and LACLMTR (5'-CCCTCCACCAGCAGGATCAAAGAAGGTAGTGTT-3') based on certain sequences of C. livia using the above LA-PCR primer set (Table 1). The LA-PCR was conducted at $94^{\circ} \mathrm{C}$ for $1 \mathrm{~min}$, followed by 35 cycles consisting of $10 \mathrm{~s}$ denaturation at $98^{\circ} \mathrm{C}$ and $13 \mathrm{~min}$ annealing and extension at $68^{\circ} \mathrm{C}$, with a final extension step of $10 \mathrm{~min}$ at $72^{\circ} \mathrm{C}$, in a DNA thermal cycler TC-3000 (Techne, Barloworld Scientific Ltd., UK). The amplified fragments with a size of approximately $12 \mathrm{~kb}$ that were obtained were used as the templates for amplification of the short overlapping fragments (1.1-1.5 kb in length) with 15 primer sets (Table 2). All 15 sets of primers were designed based on the conserved sequences of the known mitochondrial genome sequences in Galliformes or on the determined sequences of fragments of the mitogenome of C. livia in this study, which were aligned using CLUSTAL X v2.0.10 (Larkin et al., 2007). Each primer set amplified an mtDNA fragment containing an overlap of at least $100 \mathrm{bp}$ with the adjacent amplified fragment at both termini. PCR was carried out in a volume of $25 \mu \mathrm{L}$ containing 5-50 ng DNA template, 6.25 pmoL of each primer, $0.2 \mathrm{mM}$ of each dNTP, $2 \mathrm{mM}$ $\mathrm{MgCl}_{2}$, and $0.625 \mathrm{U}_{\text {Dream Taq }}{ }^{\mathrm{TM}}$ DNA polymerase (Fermentas, Burlington, Canada) or Ex Taq

\begin{tabular}{|c|c|c|c|}
\hline Fragment & Primer name & Primer sequence (5'-3') & Primer size (bp) \\
\hline \multirow{2}{*}{1} & CLMT1F & TATCACACCTCCСТACACCG & 20 \\
\hline & CLMT1R & TCGTGATGGATACTTCTCGC & 20 \\
\hline \multirow[t]{2}{*}{2} & AVMT2F & AACCCATTATATGTATACGG & 20 \\
\hline & AVMT2R & TTACTGCTGAGTACCCGTGG & 20 \\
\hline \multirow[t]{2}{*}{3} & AVMT3F & GCAAAAGACTTAGTCCTAACC & 21 \\
\hline & AVMT3R & CTTTTGCGACAGAGACGGGTT & 21 \\
\hline \multirow[t]{2}{*}{4} & AVMT4F & AAGTCGTAACAAGGTAAGTGAC & 22 \\
\hline & AVMT4R & CGCCCCAACCGAAAAATGTC & 20 \\
\hline \multirow[t]{3}{*}{5} & AVMT5F & AAGACGAGAAGACCCTGTGG & 20 \\
\hline & CLMd5F & CGCAGTACCAATCCTAATC & 19 \\
\hline & CLMT5R & CGGTTTGTTTCAGCGAGAGTT & 21 \\
\hline \multirow[t]{2}{*}{6} & AVMT6F & TAAGCACCCTGGCCATCACC & 20 \\
\hline & CLMT6R & GGTTAGAAGGGTGAGGTTTG & 20 \\
\hline \multirow[t]{2}{*}{7} & AVMT7F & ACACAGACACGAAAAATCCT & 20 \\
\hline & CLMT7R & AAGGTCTACAGAGGCTCCG & 19 \\
\hline \multirow[t]{2}{*}{8} & AVMT8F & CGCATAAATAACATAAGCTTC & 21 \\
\hline & AVMT8R & GAAGCATTAAGTGGTTTGAT & 20 \\
\hline \multirow[t]{2}{*}{9} & AVMT9F & AAGCCTTCTCAGCAAAACGA & 20 \\
\hline & AVMT9R & GCTTAGGTTCATGGTCAGGT & 20 \\
\hline \multirow[t]{2}{*}{10} & AVMT10F & ATGACATGCCCCAATTAAACC & 21 \\
\hline & AVMT10R & GATGGCTTGTTTTCGGTTTCC & 21 \\
\hline \multirow[t]{2}{*}{11} & AVMT11F & CAAGCCTAGCCCCAACACCAG & 21 \\
\hline & AVMT11R & ATGGGGTTAGTCAGTGTAGGC & 21 \\
\hline \multirow[t]{2}{*}{12} & ColMT12F & CTCATGGTTCAGATCACTTAC & 21 \\
\hline & ColMT12R & GTTCCTCGTTGGGTTATTAG & 20 \\
\hline \multirow[t]{2}{*}{13} & AVMT13F & ACTACGAACGGACACACAGCCG & 22 \\
\hline & AVMT13R & GAAGG CCAAA TTGAG CGGAT & 20 \\
\hline \multirow[t]{2}{*}{14} & AVMT14F & ATGACAAGGACGAGCTGAAG & 20 \\
\hline & AVMT14R & ATTATTTTTAGTAGGGGGTG & 20 \\
\hline \multirow[t]{3}{*}{15} & AVMT15F & GCCAA CCTTC ATCTC ACCATAA & 22 \\
\hline & CLMd15R & AGGGTTTGCAGGCGTGAAGT & 20 \\
\hline & AVMT15R & CTTGTGCGTGGGTTGTCTCGGG & 22 \\
\hline
\end{tabular}


DNA polymerase (TaKaRa, Dalian, China). Amplification was conducted in a DNA thermal cycler TC-3000, as above. PCR cycles were as follows: one cycle of 4 min at $70^{\circ} \mathrm{C}, 4$ cycles of $40 \mathrm{~s}$ at $94^{\circ} \mathrm{C}, 20 \mathrm{~s}$ at $52^{\circ} \mathrm{C}$, and $2 \mathrm{~min}$ and $10 \mathrm{~s}$ at $72^{\circ} \mathrm{C}$, followed by 36 cycles of $20 \mathrm{~s}$ at $94^{\circ} \mathrm{C}$, $20 \mathrm{~s}$ at $50-55^{\circ} \mathrm{C}$, and $2 \mathrm{~min}$ and $10 \mathrm{~s}$ at $72^{\circ} \mathrm{C}$. The process was completed with a final extension step at $72^{\circ} \mathrm{C}$ for $10 \mathrm{~min}$. The band with the right size was cut out and purified using an EZ Spin Column DNA Gel Extraction Kit (Bio Basic Inc.) and then cloned with pGEM $^{\circledR}$-T Easy Vector System II (Promega). Internal primers were applied to fragments 5 and 15 (Table 2). All distinct clones were sequenced on an ABI-PRISM 3730 sequencer using a BigDye Terminator v3.1 Cycle Sequencing Kit (Applied Biosystems) and the corresponding primer.

\section{Gene identification and genome analyses}

DNA sequences were analyzed using BioEdit 7.0.9.0 (Hall, 1999) and DAMBE 4.1.19 (Xia and Xie, 2001) softwares. Contig assembly was performed with the ContigExpress program (a component of Vector NTI Suite 6.0). The boundaries of protein-coding genes and rRNA genes were initially identified via DOGMA (Wyman et al., 2004) using the default setting, and refined by alignment with mitochondrial genomes of other avian species (Table 1). Composition skewness was calculated according to the formulas (AT skew $=[\mathrm{A}-\mathrm{T}] /[\mathrm{A}$ $+\mathrm{T}] ; \mathrm{GC}$ skew $=[\mathrm{G}-\mathrm{C}] /[\mathrm{G}+\mathrm{C}])($ Perna and Kocher, 1995). Most tRNA genes were identified using tRNAscan-SE1.21 (Lowe and Eddy, 1997) under the 'cove only' search mode, with the vertebrate mitochondrial genetic code and 'mito/chloroplast' source. Some tRNA genes that were not found by the tRNA-SE1.21 were identified by proposed secondary structures and anti-codons (Shen et al., 2009). A gene map of the mitochondrial genome of C. livia was initially generated with OGDRAW (Lohse et al., 2007) and then modified manually.

\section{RESULTS AND DISCUSSION}

\section{Genome organization and base composition}

The complete sequence of the mtDNA of $C$. livia is 17,229 bp in length (Figure 1 and Table 3) and was deposited in GenBank with the accession No. (GU908131). The size of avian mtDNA ranges from 16,595 bp (Ninox novaeseelandiae) to 18,967 bp (Thalassarche melanophrys). Similar to the typical mitochondrial genomes of other vertebrates, the Rock pigeon mtDNA consists of 13 typical protein-coding genes, 22 tRNA genes, 2 rRNA genes ( $r r R N A$ and $\operatorname{lr} R N A$; small and large rRNA subunits, respectively) and one putative control region (Dloop) (Table 3). As found in other vertebrates, most of these genes are coded on the H-strand, except for one protein-coding gene (nad6) and eight tRNA genes ( $t R N A^{G l n}, t R N A^{A l a}, t R N A^{A s n}$, $\left.t R N A^{C y s}, t R N A^{T y r} t R N A^{\operatorname{Ser}(U C N)}, t R N A^{\text {Pro }}, t R N A^{G l u}\right)$.

The overall base composition of the H-strand is as follows: A (30.15\%), T (23.98\%), $\mathrm{G}(13.98 \%), \mathrm{C}(31.90 \%)$; the $\mathrm{A}+\mathrm{T}$ content of C. livia (54.13\%) is similar to those of other birds (ranging from 52.46 to $57.56 \%$, Table 4). As in most vertebrates, the overall base composition is skewed against guanine in the C. livia mitochondrial genome, which is due to a strong bias against the use of guanine at the third codon position (San Mauro et al., 2004).

The nucleotide composition of the C. livia mitogenome is slightly biased toward $\mathrm{A}+\mathrm{T}$ nucleotides $(54.13 \%$, Table 4$)$, which is a higher percentage than that of $P$. azara $(52.46 \%)$, 


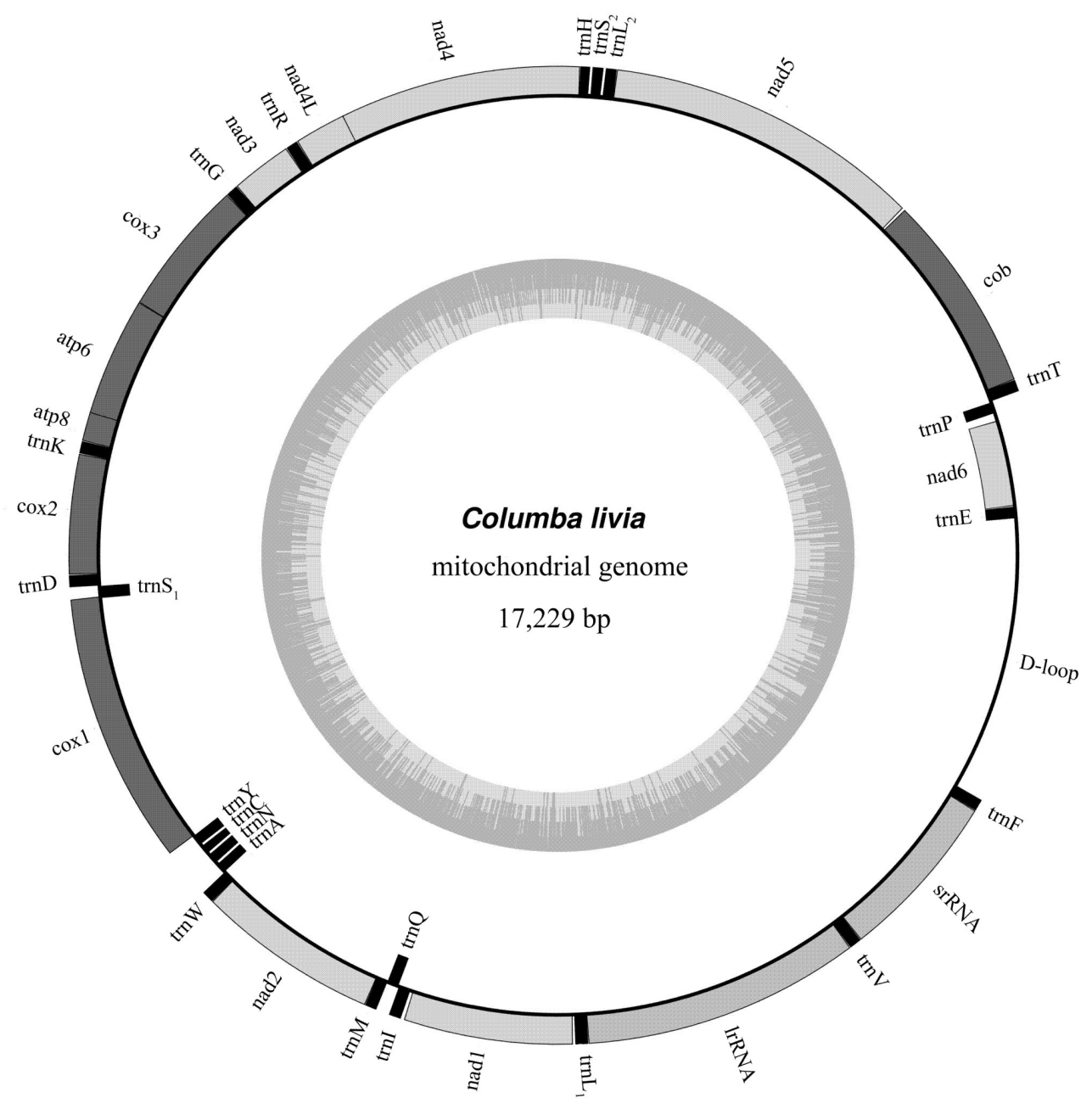

Figure 1. Gene map of the mitochondrial genome of Columba livia. Genes encoded on the heavy or light strands are shown outside and inside the circular gene map, respectively. The inner ring displays the GC content. Twenty-two tRNA genes are designated by single-letter amino acid codes. This figure was initially generated with OGDRAW and modified manually.

P. rubricauda (52.75\%), B. canadensis (52.78\%), N. novaehollandiae (52.8\%), R. americana (53.06\%), C. ciconia (53.67\%), and G. gallus (53.99\%), but lower than in the other 22 avian species, ranging from 54.17 to $57.56 \%$. Within 13 protein-coding genes in the C. livia mitochondrial genome, the $\mathrm{A}+\mathrm{T}$ composition is the highest in the atp 8 gene $(55.95 \%)$, and the lowest in the cob gene $(51.53 \%)$. 
Table 3. Localization and features of genes in the mitochondrial genome of Columba livia.

\begin{tabular}{|c|c|c|c|c|c|c|c|c|c|}
\hline \multirow[t]{2}{*}{ Gene/region } & \multirow[t]{2}{*}{ Strand } & \multicolumn{2}{|c|}{ Position } & \multicolumn{2}{|c|}{ Size } & \multicolumn{2}{|c|}{ Codon } & \multirow[t]{2}{*}{ Anticodon } & \multirow{2}{*}{$\begin{array}{l}\text { Intergenic } \\
\text { nucleotides }\end{array}$} \\
\hline & & From & To & Nucleotide & Amino acids & Start & Stopa & & \\
\hline$t R N A^{\text {Phe }}$ & $\mathrm{H}$ & 1 & 69 & 69 & & & & GAA & 0 \\
\hline srRNA & $\mathrm{H}$ & 70 & 1,042 & 973 & & & & & 0 \\
\hline$t R N A^{V a l}$ & $\mathrm{H}$ & 1,043 & 1,114 & 72 & & & & TAC & 0 \\
\hline $\operatorname{lr} R N A$ & $\mathrm{H}$ & 1,115 & 2,700 & 1586 & & & & & 0 \\
\hline$t R N A^{\operatorname{Len}(U U R)}$ & $\mathrm{H}$ & 2,701 & 2,774 & 74 & & & & TAA & 11 \\
\hline nadl & $\mathrm{H}$ & 2,786 & 3,751 & 966 & 324 & ATG & AGA & & 17 \\
\hline$t R N A^{\text {He }}$ & $\mathrm{H}$ & 3,769 & 3,839 & 71 & & & & GAT & 5 \\
\hline$t R N A^{G l n}$ & $\mathrm{~L}$ & 3,845 & 3,915 & 71 & & & & TTG & -1 \\
\hline$t R N A^{\text {Met }}$ & $\mathrm{H}$ & 3,915 & 3,983 & 69 & & & & CAT & 0 \\
\hline $\operatorname{nad} 2$ & $\mathrm{H}$ & 3,984 & 5,023 & 1040 & 346 & ATG & TA- & & 0 \\
\hline$t R N A^{T T p}$ & $\mathrm{H}$ & 5,024 & 5,094 & 71 & & & & TCA & 1 \\
\hline tRNA & $\mathrm{L}$ & 5,096 & 5,164 & 69 & & & & $\mathrm{TGC}$ & 2 \\
\hline$t R N A^{A s n}$ & $\mathrm{~L}$ & 5,167 & 5,239 & 73 & & & & GTT & 2 \\
\hline$t R N A^{C_{y s}}$ & $\mathrm{~L}$ & 5,242 & 5,308 & 67 & & & & GCA & -1 \\
\hline$t R N A^{T_{y} r}$ & $\mathrm{~L}$ & 5,308 & 5,379 & 72 & & & & GTA & 1 \\
\hline $\operatorname{coxl}$ & $\mathrm{H}$ & 5,381 & 6,931 & 1551 & 516 & GTG & AGG & & -9 \\
\hline$t R N A^{\operatorname{Ser}(U C N)}$ & $\mathrm{L}$ & 6,923 & 6,996 & 74 & & & & TGA & 2 \\
\hline$t R N A^{A s p}$ & $\mathrm{H}$ & 6,999 & 7,067 & 69 & & & & GTC & 2 \\
\hline $\cos 2$ & $\mathrm{H}$ & 7,070 & 7,753 & 684 & 227 & ATG & TAA & & 1 \\
\hline$t R N A^{L y s}$ & $\mathrm{H}$ & 7,755 & 7,825 & 71 & & & & TTT & 1 \\
\hline atp8 & $\mathrm{H}$ & 7,827 & 7,994 & 168 & 54 & ATG & TAA & & -10 \\
\hline atp6 & $\mathrm{H}$ & 7,985 & 8,668 & 684 & 227 & ATG & TAA & & -1 \\
\hline $\cos 3$ & $\mathrm{H}$ & 8,668 & 9,451 & 784 & 261 & ATG & T- & & 0 \\
\hline$t R N A^{G l y}$ & $\mathrm{H}$ & 9,452 & 9,520 & 69 & & & & TCC & 0 \\
\hline$n a d 3$ & $\mathrm{H}$ & 9,521 & 9,872 & 352 & & ATT & TAA & & 1 \\
\hline$t R N A^{A r g}$ & $\mathrm{H}$ & 9,874 & 9,942 & 69 & & & & TCG & 1 \\
\hline $\operatorname{nad} 4 \mathrm{~L}$ & $\mathrm{H}$ & 9,944 & 10,240 & 297 & 98 & ATG & TAA & & -7 \\
\hline nad4 & $\mathrm{H}$ & 10,234 & 11,611 & 1378 & 459 & ATG & T- & & 0 \\
\hline$t R N A^{H i s}$ & $\mathrm{H}$ & 11,612 & 11,680 & 69 & & & & GTG & 0 \\
\hline$t R N A^{\operatorname{Ser}(A G Y)}$ & $\mathrm{H}$ & 11,681 & 11,746 & 66 & & & & GCT & -1 \\
\hline$t R N A^{\operatorname{Len}(C U N)}$ & $\mathrm{H}$ & 11,746 & 11,817 & 72 & & & & TAG & 0 \\
\hline nad5 & $\mathrm{H}$ & 11,818 & 13,632 & 1815 & 604 & GTG & AGA & & 11 \\
\hline$c o b$ & $\mathrm{H}$ & 13,644 & 14,786 & 1143 & 380 & ATG & TAA & & 0 \\
\hline$t R N A^{T h r}$ & $\mathrm{H}$ & 14,787 & 14,855 & 69 & & & & TGT & 6 \\
\hline$t R N A^{P r o}$ & $\mathrm{~L}$ & 14,862 & 14,931 & 70 & & & & TGG & 45 \\
\hline nad6 & L & 14,977 & 15,498 & 522 & 173 & ATG & TAG & & 3 \\
\hline$t R N A^{G l u}$ & $\mathrm{~L}$ & 15,502 & 15,572 & 71 & & & & TTC & 0 \\
\hline D-loop & $\mathrm{H}$ & 15,573 & 17,229 & 1657 & & & & & 0 \\
\hline
\end{tabular}

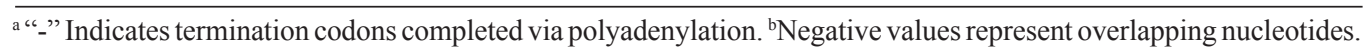

The AT skew and GC skew were calculated for the complete mitogenomes of 30 avian species, representing 29 orders (Table 4). The AT skew for the C. livia mitochondrial genome is slightly positive (0.114), indicating the occurrence of more As than Ts. We found similar results in the other 29 avian species (0.068 to 0.180$)$. In contrast, the GC skew in all 30 avian mitochondrial genomes was strongly negative (-0.346 to 0.438$)$, meaning that there is a heavy bias toward Cs and against Gs. Furthermore, one extra nucleotide ' $\mathrm{C}$ ' is present in nad 3 of $C$. livia, which is consistently observed in many other birds and some turtles and is thought not to be translated (Slack et al., 2003). The function of the extra "C" in nad3 and its phylogenetic implications are still unclear. 


\begin{tabular}{|c|c|c|c|c|c|c|c|c|}
\hline Species & Size $(b p)^{\mathrm{a}}$ & $\mathrm{A} \%$ & $\mathrm{C} \%$ & $\mathrm{G} \%$ & $\mathrm{~T} \%$ & $\mathrm{~A}+\mathrm{T} \%$ & AT skew & GC skew \\
\hline \multicolumn{9}{|l|}{ Whole genome } \\
\hline A. apus & 17,037 & 31.37 & 31.52 & 13.19 & 23.92 & 55.29 & 0.135 & -0.410 \\
\hline A. colubris & $\underline{16,356}$ & 30.62 & 31.27 & 14.22 & 23.86 & 54.48 & 0.124 & -0.375 \\
\hline A. cristatus & 18,607 & 30.67 & 30.54 & 13.63 & 25.10 & 55.77 & 0.100 & -0.383 \\
\hline A. haastii & 16,980 & 30.91 & 29.48 & 13.33 & 26.24 & 57.15 & 0.082 & -0.377 \\
\hline B. canadensis & 16,760 & 30.18 & 32.07 & 15.14 & 22.60 & 52.78 & 0.144 & -0.359 \\
\hline C. casuarius & 16,756 & 30.47 & 29.73 & 14.45 & 25.25 & 55.72 & 0.094 & -0.346 \\
\hline C. ciconia & 17,347 & 30.54 & 31.98 & 14.35 & 23.13 & 53.67 & 0.138 & -0.381 \\
\hline C. livia & 17,229 & 30.15 & 31.90 & 13.98 & 23.98 & 54.13 & 0.114 & -0.391 \\
\hline D. giganteus & 17,070 & 30.67 & 31.25 & 13.93 & 24.15 & 54.82 & 0.119 & -0.383 \\
\hline E. minor & 17,611 & 30.96 & 31.84 & 13.53 & 23.67 & 54.63 & 0.133 & -0.404 \\
\hline E. orientalis & 17,774 & 30.26 & 31.74 & 13.82 & 24.18 & 54.44 & 0.112 & -0.393 \\
\hline F. peregrinus & 18,068 & 32.74 & 30.87 & 13.57 & 22.77 & 55.51 & 0.180 & -0.389 \\
\hline G. californianus & 17,091 & 32.34 & 31.70 & 12.40 & 23.55 & 55.89 & 0.157 & -0.438 \\
\hline G. gallus & 16,785 & 30.25 & 32.49 & 13.52 & 23.74 & 53.99 & 0.121 & -0.412 \\
\hline G. stellata & 17,573 & 30.36 & 31.43 & 14.39 & 23.81 & 54.17 & 0.121 & -0.372 \\
\hline H. ater & 16,791 & 31.59 & 31.12 & 13.67 & 23.62 & 55.21 & 0.144 & -0.390 \\
\hline H. novaeseelandiae & 17,264 & 30.97 & 31.89 & 13.21 & 23.92 & 54.89 & 0.128 & -0.414 \\
\hline M. undulates & 18,193 & 31.13 & 31.73 & 12.96 & 24.19 & 55.32 & 0.125 & -0.420 \\
\hline M. novaehollandiae & 17,839 & 30.11 & 30.36 & 14.45 & 25.08 & 55.19 & 0.091 & -0.355 \\
\hline N. novaehollandiae & $\underline{16,223}$ & 30.83 & 33.40 & 13.78 & 21.97 & 52.80 & 0.168 & -0.416 \\
\hline P. azara & 18,736 & 28.44 & 34.10 & 13.44 & 24.02 & 52.46 & 0.084 & -0.435 \\
\hline P. rubber & 17,446 & 31.54 & 32.03 & 13.49 & 22.93 & 54.47 & 0.158 & -0.407 \\
\hline P. rubricauda & 17,777 & 29.41 & 32.95 & 14.29 & 23.34 & 52.75 & 0.115 & -0.395 \\
\hline R. american $a$ & 16,714 & 28.69 & 32.20 & 14.74 & 24.37 & 53.06 & 0.081 & -0.372 \\
\hline R. jubatus & 16,937 & 30.32 & 30.36 & 14.15 & 25.17 & 55.49 & 0.093 & -0.364 \\
\hline S. camelus & 16,595 & 30.47 & 30.40 & 14.21 & 24.92 & 55.39 & 0.100 & -0.363 \\
\hline T. major & 16,701 & 30.48 & 29.88 & 13.05 & 26.56 & 57.04 & 0.069 & -0.392 \\
\hline T. melanophrys & 18,967 & 31.45 & 30.53 & 13.64 & 24.38 & 55.83 & 0.127 & -0.382 \\
\hline T. novaehollandiae & 18,002 & 31.75 & 32.06 & 13.12 & 23.08 & 54.83 & 0.158 & -0.419 \\
\hline T. viridis & 17,751 & 30.73 & 28.82 & 13.62 & 26.83 & 57.56 & 0.068 & -0.358 \\
\hline \multicolumn{9}{|l|}{ Protein-coding genes } \\
\hline A. apus & 11,388 & 29.00 & 32.74 & 13.03 & 25.22 & 54.22 & 0.070 & -0.431 \\
\hline A. colubris & 11,394 & 28.59 & 32.23 & 13.83 & 25.35 & 53.94 & 0.060 & -0.400 \\
\hline A. cristatus & 11,388 & 28.77 & 32.04 & 13.57 & 25.62 & 54.39 & 0.058 & -0.405 \\
\hline A. haastii & 11,385 & 29.16 & 30.41 & 13.10 & 27.33 & 56.49 & 0.032 & -0.400 \\
\hline B. canadensis & 11,412 & 27.97 & 33.04 & 15.12 & 23.86 & 51.83 & 0.079 & -0.372 \\
\hline C. casuarius & 11,394 & 28.23 & 30.65 & 14.12 & 27.01 & 55.24 & 0.022 & -0.369 \\
\hline C. ciconia & 11,400 & 28.42 & 33.89 & 13.63 & 24.05 & 52.47 & 0.083 & -0.426 \\
\hline C. livia & 11,388 & 27.96 & 32.98 & 13.68 & 25.38 & 53.34 & 0.048 & -0.414 \\
\hline D. giganteus & 11,397 & 28.28 & 32.27 & 13.85 & 25.60 & 53.88 & 0.050 & -0.400 \\
\hline E. minor & 11,400 & 29.16 & 33.83 & 13.01 & 24.00 & 53.16 & 0.097 & -0.444 \\
\hline E. orientalis & 11,397 & 28.20 & 33.25 & 13.73 & 24.80 & 53.00 & 0.064 & -0.416 \\
\hline F. peregrinus & 11,406 & 29.49 & 32.52 & 13.19 & 24.80 & 54.29 & 0.086 & -0.423 \\
\hline G. californianus & 11,403 & 30.23 & 32.29 & 12.56 & 24.92 & 55.15 & 0.096 & -0.440 \\
\hline G. gallus & 11,397 & 28.31 & 33.58 & 13.37 & 24.74 & 53.05 & 0.067 & 0.430 \\
\hline G. stellata & 11,400 & 28.48 & 33.49 & 13.78 & 24.25 & 52.73 & 0.080 & -0.417 \\
\hline H. ater & 11,400 & 29.75 & 32.15 & 13.14 & 24.96 & 54.71 & 0.088 & -0.420 \\
\hline H. novaeseelandiae & 11,391 & 28.99 & 32.67 & 13.21 & 25.13 & 54.12 & 0.071 & -0.424 \\
\hline M. undulates & 11,400 & 29.89 & 33.60 & 12.26 & 24.25 & 54.14 & 0.104 & -0.465 \\
\hline M. novaehollandiae & 11,394 & 27.92 & 32.25 & 14.40 & 25.43 & 53.35 & 0.047 & -0.383 \\
\hline N. novaehollandiae & 11,406 & 29.03 & 33.72 & 13.49 & 23.73 & 52.76 & 0.100 & -0.429 \\
\hline R. jubatus & 11,379 & 26.09 & 36.34 & 13.60 & 23.97 & 50.06 & 0.042 & -0.455 \\
\hline P. azara & 11,400 & 29.18 & 32.92 & 13.49 & 24.41 & 53.59 & 0.089 & -0.419 \\
\hline P. rubber & 11,397 & 27.12 & 34.61 & 14.64 & 23.64 & 50.76 & 0.069 & -0.405 \\
\hline P. rubricauda & 11,403 & 26.01 & 33.78 & 14.57 & 25.64 & 51.65 & 0.007 & -0.397 \\
\hline R. americana & 11,397 & 28.53 & 31.70 & 13.64 & 26.14 & 54.66 & 0.044 & -0.398 \\
\hline S. camelus & 11,400 & 28.01 & 31.21 & 14.24 & 26.54 & 54.55 & 0.027 & -0.373 \\
\hline T. major & 11,382 & 28.40 & 30.50 & 12.91 & 28.20 & 56.60 & 0.004 & -0.405 \\
\hline T. melanophrys & 11,406 & 29.14 & 31.45 & 13.56 & 25.85 & 54.99 & 0.060 & -0.397 \\
\hline T. novaehollandiae & 11,388 & 30.30 & 33.42 & 12.78 & 23.50 & 53.80 & 0.126 & -0.447 \\
\hline T. viridis & 11,406 & 29.07 & 29.38 & 13.46 & 28.09 & 57.16 & 0.017 & -0.372 \\
\hline
\end{tabular}

Continued on next page 
X.Z. Kan et al.

Table 4. Continued.

\begin{tabular}{|c|c|c|c|c|c|c|c|c|}
\hline Species & Size (bp) & $\mathrm{A} \%$ & $\mathrm{C} \%$ & $\mathrm{G} \%$ & $\mathrm{~T} \%$ & $\mathrm{~A}+\mathrm{T} \%$ & AT skew & GC skew \\
\hline \multicolumn{9}{|l|}{ tRNA } \\
\hline A. apus & 1,548 & 29.78 & 21.58 & 21.32 & 27.33 & 57.11 & 0.043 & -0.006 \\
\hline A. colubris & 1,551 & 30.37 & 20.95 & 21.41 & 27.08 & 57.45 & 0.057 & 0.011 \\
\hline A. cristatus & 1,539 & 29.82 & 20.86 & 21.25 & 28.07 & 57.89 & 0.030 & 0.009 \\
\hline A. haastii & 1,551 & 33.27 & 24.31 & 16.57 & 25.85 & 59.12 & 0.126 & -0.189 \\
\hline B. canadensis & 1,540 & 30.65 & 21.56 & 20.78 & 27.01 & 57.66 & 0.063 & -0.018 \\
\hline C. casuarius & 1,539 & 30.86 & 21.25 & 19.56 & 28.33 & 59.19 & 0.043 & -0.041 \\
\hline C. ciconia & 1,550 & 29.81 & 21.35 & 21.42 & 27.42 & 57.23 & 0.042 & 0.002 \\
\hline C. livia & 1,547 & 28.70 & 21.78 & 22.24 & 27.28 & 55.98 & 0.025 & 0.010 \\
\hline D. giganteus & 1,552 & 30.22 & 20.94 & 21.07 & 27.77 & 57.99 & 0.042 & 0.003 \\
\hline E. minor & 1,548 & 29.20 & 21.77 & 21.96 & 27.07 & 56.27 & 0.038 & 0.004 \\
\hline E. orientalis & 1,550 & 29.23 & 21.61 & 21.74 & 27.42 & 56.65 & 0.032 & 0.003 \\
\hline F. peregrinus & 1,563 & 29.17 & 21.63 & 21.69 & 27.51 & 56.69 & 0.029 & 0.001 \\
\hline G. californianus & 1,542 & 30.80 & 21.34 & 20.75 & 27.11 & 57.91 & 0.064 & -0.014 \\
\hline G. gallus & 1,543 & 30.14 & 21.84 & 20.67 & 27.35 & 57.49 & 0.049 & -0.028 \\
\hline G. stellata & 1,554 & 29.79 & 21.75 & 21.43 & 27.03 & 56.82 & 0.049 & -0.007 \\
\hline H. ater & 1,549 & 30.08 & 20.92 & 20.79 & 28.21 & 58.30 & 0.032 & -0.003 \\
\hline H. novaeseelandiae & 1,549 & 29.70 & 20.98 & 21.37 & 27.95 & 57.65 & 0.030 & 0.009 \\
\hline M. undulates & 1,541 & 30.24 & 21.35 & 20.44 & 27.97 & 58.21 & 0.039 & -0.022 \\
\hline M. novaehollandiae & 1,548 & 29.72 & 20.93 & 21.45 & 27.91 & 57.62 & 0.031 & 0.012 \\
\hline N. novaehollandiae & 1,557 & 29.42 & 22.41 & 21.71 & 26.46 & 55.88 & 0.053 & -0.016 \\
\hline P. azara & 1,546 & 29.50 & 21.54 & 21.73 & 27.23 & 56.73 & 0.040 & 0.004 \\
\hline P. rubber & 1,551 & 29.72 & 21.79 & 21.28 & 27.21 & 56.93 & 0.044 & -0.012 \\
\hline P. rubricauda & 1,543 & 28.78 & 22.81 & 21.97 & 26.44 & 55.22 & 0.042 & -0.019 \\
\hline R. american a & 1,538 & 29.91 & 20.42 & 21.46 & 28.22 & 58.13 & 0.029 & 0.025 \\
\hline R. jubatus & 1,555 & 29.65 & 21.29 & 21.74 & 27.33 & 56.98 & 0.040 & 0.010 \\
\hline S. camelus & 1,538 & 30.82 & 20.22 & 20.81 & 28.15 & 58.97 & 0.045 & 0.014 \\
\hline T. major & 1,537 & 30.45 & 20.04 & 20.82 & 28.69 & 59.14 & 0.030 & 0.019 \\
\hline T. melanophrys & 1,757 & 30.17 & 20.38 & 21.29 & 28.17 & 58.34 & 0.034 & 0.022 \\
\hline T. novaehollandiae & 1,532 & 29.63 & 21.48 & 21.67 & 27.22 & 56.85 & 0.042 & 0.004 \\
\hline T. viridis & 1,555 & 30.42 & 20.51 & 20.96 & 28.10 & 58.52 & 0.040 & 0.011 \\
\hline \multicolumn{9}{|l|}{ rRNA } \\
\hline A. apus & 2,572 & 33.90 & 27.10 & 18.47 & 20.53 & 54.43 & 0.246 & -0.189 \\
\hline A. colubris & 2,553 & 33.37 & 26.48 & 19.31 & 20.84 & 54.21 & 0.231 & -0.157 \\
\hline A. cristatus & 2,561 & 32.02 & 27.22 & 19.25 & 21.28 & 53.30 & 0.202 & -0.172 \\
\hline A. haastii & 2,638 & 34.72 & 25.21 & 17.78 & 22.29 & 57.01 & 0.218 & -0.173 \\
\hline B. canadensis & 2,591 & 33.08 & 26.24 & 20.46 & 20.22 & 53.30 & 0.241 & -0.124 \\
\hline C. casuarius & 2,559 & 34.54 & 25.21 & 18.80 & 21.45 & 56.00 & 0.234 & -0.146 \\
\hline C. ciconia & 2,576 & 33.27 & 27.91 & 18.94 & 19.88 & 53.14 & 0.252 & -0.191 \\
\hline C. livia & 2,559 & 32.75 & 26.26 & 19.42 & 21.57 & 54.32 & 0.206 & -0.150 \\
\hline D. giganteus & 2,567 & 34.75 & 27.04 & 17.96 & 20.26 & 55.01 & 0.263 & -0.202 \\
\hline E. minor & 2,583 & 32.91 & 27.84 & 19.09 & 20.17 & 53.08 & 0.240 & -0.186 \\
\hline E. orientalis & 2,562 & 32.90 & 27.40 & 19.59 & 21.10 & 53.01 & 0.219 & -0.166 \\
\hline F. peregrinus & 2,578 & 33.67 & 27.97 & 18.89 & 18.47 & 53.14 & 0.292 & -0.194 \\
\hline G. californianus & 2,572 & 33.75 & 26.56 & 18.04 & 21.66 & 55.40 & 0.218 & -0.191 \\
\hline G. gallus & 2,598 & 33.06 & 28.37 & 18.17 & 20.40 & 53.46 & 0.237 & -0.219 \\
\hline G. stellata & 2,588 & 33.04 & 27.47 & 19.32 & 20.17 & 53.21 & 0.242 & -0.174 \\
\hline H. ater & 2,552 & 33.03 & 26.61 & 19.47 & 20.89 & 53.92 & 0.225 & -0.155 \\
\hline H. novaeseelandiae & 2,575 & 33.94 & 27.34 & 18.14 & 20.58 & 54.52 & 0.245 & -0.202 \\
\hline M. undulates & 2,549 & 33.58 & 30.29 & 18.12 & 18.01 & 51.59 & 0.302 & -0.251 \\
\hline M. novaehollandiae & 2,575 & 32.35 & 25.48 & 20.31 & 21.86 & 54.21 & 0.194 & -0.113 \\
\hline N. novaehollandiae & 2,557 & 32.93 & 29.25 & 19.63 & 18.19 & 51.11 & 0.288 & -0.197 \\
\hline P. azara & 2,556 & 32.08 & 29.93 & 18.97 & 19.01 & 51.10 & 0.256 & -0.224 \\
\hline P. rubber & 2,567 & 33.27 & 26.76 & 19.05 & 20.92 & 54.19 & 0.228 & -0.168 \\
\hline P. rubricauda & 2,581 & 33.05 & 29.99 & 18.09 & 18.87 & 51.92 & 0.273 & -0.248 \\
\hline R. american a & 2,546 & 32.88 & 26.75 & 19.17 & 21.21 & 54.08 & 0.216 & -0.165 \\
\hline R. jubatus & 2,553 & 31.84 & 25.85 & 19.98 & 22.33 & 54.17 & 0.176 & -0.128 \\
\hline S. camelus & 2,546 & 34.33 & 26.28 & 18.07 & 21.33 & 55.66 & 0.234 & -0.185 \\
\hline T. major & 2,575 & 34.06 & 26.06 & 18.02 & 21.86 & 55.92 & 0.218 & -0.182 \\
\hline T. melanophrys & 2,573 & 33.15 & 26.16 & 19.43 & 21.26 & 54.41 & 0.219 & -0.148 \\
\hline T. novaehollandiae & 2,563 & 34.14 & 28.25 & 18.14 & 19.47 & 53.61 & 0.274 & -0.218 \\
\hline T. viridis & 2,600 & 33.00 & 25.50 & 19.00 & 22.50 & 55.50 & 0.189 & -0.146 \\
\hline
\end{tabular}

Continued on next page 
Table 4. Continued.

\begin{tabular}{|c|c|c|c|c|c|c|c|c|}
\hline Species & Size (bp) & $\mathrm{A} \%$ & $\mathrm{C} \%$ & $\mathrm{G} \%$ & $\mathrm{~T} \%$ & $\mathrm{~A}+\mathrm{T} \%$ & AT skew & GC skew \\
\hline \multicolumn{9}{|l|}{ Control region } \\
\hline A. apus & 21,470 & 34.49 & 24.56 & 11.90 & 29.05 & 63.54 & 0.086 & -0.347 \\
\hline A. colubris & 787 & 29.35 & 26.18 & 15.25 & 29.10 & 58.45 & 0.004 & -0.264 \\
\hline A. cristatus & 3,054 & 31.57 & 25.87 & 11.72 & 30.71 & 62.28 & 0.014 & -0.376 \\
\hline A. haastii & 1,351 & 25.54 & 25.91 & 12.66 & 35.90 & 61.44 & -0.169 & -0.344 \\
\hline B. canadensis & 1,194 & 29.65 & 31.49 & 13.48 & 25.38 & 55.03 & 0.078 & -0.400 \\
\hline C. casuarius & 1,138 & 28.21 & 26.98 & 15.20 & 29.61 & 57.82 & -0.024 & -0.279 \\
\hline C. ciconia & 1,779 & 31.08 & 22.60 & 17.93 & 28.39 & 59.47 & 0.045 & -0.115 \\
\hline C. livia & 1,657 & 30.84 & 28.49 & 13.28 & 27.40 & 58.24 & 0.059 & -0.364 \\
\hline D. giganteus & 1508 & 30.11 & 27.45 & 14.32 & 28.12 & 58.22 & 0.034 & -0.314 \\
\hline E. minor & 2,040 & 31.13 & 23.04 & 13.24 & 32.60 & 63.73 & -0.023 & -0.270 \\
\hline E. orientalis & 2,190 & 30.78 & 25.89 & 11.60 & 31.74 & 62.51 & -0.015 & -0.381 \\
\hline F. peregrinus & 2,460 & 39.88 & 22.48 & 14.02 & 23.25 & 63.13 & 0.263 & -0.232 \\
\hline G. californianus & 1,169 & 28.74 & 28.49 & 11.89 & 30.88 & 59.62 & -0.036 & -0.411 \\
\hline G. gallus & 1,232 & 26.46 & 26.62 & 13.47 & 33.44 & 59.90 & -0.117 & -0.328 \\
\hline G. stellata & 1,984 & 29.89 & 21.57 & 15.98 & 32.56 & 62.45 & -0.043 & -0.149 \\
\hline H. ater & 1,240 & 32.02 & 25.97 & 14.68 & 27.34 & 59.35 & 0.079 & -0.278 \\
\hline H. novaeseelandiae & 1,690 & 30.41 & 29.88 & 11.78 & 27.87 & 58.28 & 0.044 & -0.434 \\
\hline M. undulates & 2,685 & 26.48 & 23.35 & 14.23 & 35.94 & 62.42 & -0.152 & -0.243 \\
\hline M. novaehollandiae & 2,280 & 31.32 & 24.91 & 11.36 & 32.41 & 63.73 & -0.017 & -0.374 \\
\hline N. novaehollandiae & 662 & 29.46 & 30.82 & 14.80 & 24.92 & 54.38 & 0.083 & -0.351 \\
\hline P. azara & 3,224 & 27.57 & 27.14 & 12.44 & 32.85 & 60.42 & -0.087 & -0.371 \\
\hline P. rubber & 1,878 & 34.40 & 30.24 & 11.24 & 24.07 & 58.47 & 0.177 & -0.458 \\
\hline P. rubricauda & 2,211 & 29.76 & 25.33 & 11.85 & 33.06 & 62.82 & -0.053 & -0.363 \\
\hline R. american a & 1,171 & 30.06 & 27.50 & 14.52 & 27.92 & 57.98 & 0.037 & -0.309 \\
\hline R. jubatus & 1,414 & 29.84 & 21.64 & 15.49 & 33.03 & 62.87 & -0.051 & -0.166 \\
\hline S. camelus & 1,034 & 28.82 & 26.50 & 14.31 & 30.37 & 59.19 & -0.026 & -0.299 \\
\hline T. major & 1,102 & 29.67 & 25.50 & 12.07 & 32.76 & 62.43 & -0.049 & -0.357 \\
\hline T. melanophrys & 2,629 & 31.95 & 26.63 & 13.35 & 28.07 & 60.02 & 0.065 & -0.332 \\
\hline T. novaehollandiae & 2,437 & 28.60 & 25.44 & 14.53 & 31.43 & 60.03 & -0.047 & -0.273 \\
\hline T. viridis & 2,128 & 29.56 & 25.89 & 11.94 & 32.61 & 62.17 & -0.049 & -0.369 \\
\hline
\end{tabular}

The control region of $A$. colubris and $N$. novaehollandiae are incomplete.

\section{Protein-coding genes}

The total length of the 13 protein-coding genes in C. livia mtDNA is $11,388 \mathrm{bp}$, accounting for $66.1 \%$ of the complete mitochondrial genome (Table 4$)$. The length of the 13 protein-coding genes found in avian species varies from 11,379 (Rhynochetos jubatus) to 11,412 bp (Branta canadensis). The 13 protein-coding genes found in the $C$. livia mtDNA are similar in length to most other avian species. The longest protein-coding gene of C. livia mtDNA is the nad5 gene (1815 bp), whereas the shortest is the atp 8 gene (168 bp; Table 5).

Analysis of the base composition at each codon position of the concatenated 13 protein-coding genes of $C$. livia mitochondrial genome shows that each codon position has a different AT/GC bias (Table 6). The first and third codon positions of $C$. livia are biased toward $\mathrm{A}$ and $\mathrm{C}$, while the second codon positons are biased toward $\mathrm{T}$ and $\mathrm{C}$. The AT composition at the first codon position is $49.1 \%$. The values of the second and third codon positions are 58.5 and $52.5 \%$, respectively (Table 6). As with most avian species (except for A. haastii, T. major and $T$. viridis), the second codon position has the highest AT composition (Table 6). The nad6 gene of $C$. livia mitogenome has strong skews of $\mathrm{T} v s \mathrm{~A}(-0.587)$, and $\mathrm{G} v s \mathrm{C}(0.602)$, while the nadl gene has a slight skew of T vs A (-0.016), and a strong skew of C vs G (0.452). All other 11 protein-coding genes of the $C$. livia mitochondrial genome have a slight skew of A vs $\mathrm{T}(0.005$ to 0.151$)$, and a strong skew of $\mathrm{C} v s \mathrm{G}(\mathrm{GC}$ skew $=-0.328$ to -0.757 ; Table 5$)$. 
Table 5. Base composition for protein-coding genes found in the mitochondrial genome of Columba livia.

\begin{tabular}{|c|c|c|c|c|c|c|c|c|}
\hline \multirow[t]{2}{*}{ Gene } & \multirow[t]{2}{*}{ Length (bp) } & \multicolumn{5}{|c|}{ Proportion of nucleotides (\%) } & \multirow[t]{2}{*}{ AT skew } & \multirow[t]{2}{*}{ GC skew } \\
\hline & & $\mathrm{A}$ & $\mathrm{C}$ & $\mathrm{G}$ & $\mathrm{T}$ & $\overline{\mathrm{A}+\mathrm{T}}$ & & \\
\hline nadl & 966 & 25.98 & 34.27 & 12.94 & 26.81 & 52.80 & -0.016 & -0.452 \\
\hline $\operatorname{nad} 2$ & 1041 & 31.70 & 34.20 & 10.18 & 23.92 & 55.62 & 0.140 & -0.541 \\
\hline $\operatorname{coxl}$ & 1551 & 26.11 & 31.98 & 16.18 & 25.73 & 51.84 & 0.007 & -0.328 \\
\hline $\cos 2$ & 684 & 30.41 & 30.85 & 14.62 & 24.12 & 54.53 & 0.115 & -0.357 \\
\hline $\operatorname{atp} 8$ & 168 & 32.14 & 38.69 & 5.36 & 23.81 & 55.95 & 0.149 & -0.757 \\
\hline atp6 & 684 & 28.65 & 35.09 & 9.80 & 26.46 & 55.12 & 0.040 & -0.563 \\
\hline $\operatorname{cox} 3$ & 786 & 26.97 & 33.21 & 15.01 & 24.81 & 51.78 & 0.042 & -0.377 \\
\hline nad3 & 351 & 27.07 & 33.90 & 12.25 & 26.78 & 53.85 & 0.005 & -0.469 \\
\hline nad $4 L$ & 297 & 27.61 & 33.33 & 14.48 & 24.58 & 52.19 & 0.058 & -0.394 \\
\hline nad4 & 1380 & 30.51 & 35.72 & 10.72 & 23.04 & 53.55 & 0.139 & -0.538 \\
\hline nad5 & 1815 & 31.13 & 34.49 & 11.40 & 22.98 & 54.10 & 0.151 & -0.503 \\
\hline$c o b$ & 1143 & 26.95 & 35.87 & 12.60 & 24.58 & 51.53 & 0.046 & -0.480 \\
\hline nad6 & 522 & 10.92 & 9.39 & 37.74 & 41.95 & 52.87 & -0.587 & 0.602 \\
\hline Mean & 876 & 27.40 & 32.38 & 14.10 & 26.12 & 53.52 & & \\
\hline
\end{tabular}

\begin{tabular}{|c|c|c|c|c|c|c|c|c|c|c|c|c|c|c|c|}
\hline \multirow[t]{2}{*}{ Species } & \multicolumn{5}{|c|}{ 1st codon position } & \multicolumn{5}{|c|}{ 2nd codon position } & \multicolumn{5}{|c|}{ 3rd codon position } \\
\hline & $\mathrm{A} \%$ & $\mathrm{~T} \%$ & $\mathrm{G} \%$ & $\mathrm{C} \%$ & $\mathrm{AT} \%$ & $\overline{\mathrm{A} \%}$ & $\mathrm{~T} \%$ & $\mathrm{G} \%$ & $\mathrm{C} \%$ & $\overline{\mathrm{AT} \%}$ & $\overline{\mathrm{A} \%}$ & $\mathrm{~T} \%$ & $\mathrm{G} \%$ & $\mathrm{C} \%$ & $\mathrm{AT} \%$ \\
\hline A. apus & 28.5 & 21.2 & 21.9 & 28.4 & 49.7 & 18.3 & 39.7 & 12.8 & 29.2 & 58.0 & 40.2 & 14.8 & 4.3 & 40.7 & 55.0 \\
\hline A. colubris & 28.0 & 21.9 & 22.1 & 28.0 & 49.9 & 18.5 & 39.8 & 12.6 & 29.0 & 58.3 & 39.2 & 14.4 & 6.8 & 39.6 & 53.6 \\
\hline A. cristatus & 28.7 & 20.9 & 22.1 & 28.3 & 49.6 & 18.3 & 39.8 & 12.7 & 29.2 & 58.1 & 39.3 & 16.2 & 5.9 & 38.6 & 55.5 \\
\hline A. haastii & 28.6 & 22.3 & 21.4 & 27.6 & 50.9 & 18.3 & 40.5 & 12.8 & 28.4 & 58.8 & 40.6 & 19.2 & 5.0 & 35.2 & 59.8 \\
\hline B. canadensis & 27.3 & 20.3 & 23.8 & 28.7 & 47.6 & 18.2 & 40.4 & 12.8 & 28.6 & 58.6 & 38.4 & 11.0 & 8.8 & 41.8 & 49.4 \\
\hline C. casuarius & 27.9 & 21.4 & 22.6 & 28.1 & 49.3 & 18.2 & 40.3 & 12.8 & 28.6 & 58.5 & 38.6 & 19.3 & 7.0 & 35.2 & 57.9 \\
\hline C. ciconia & 28.4 & 19.6 & 22.3 & 29.7 & 48.0 & 18.3 & 39.4 & 12.8 & 29.4 & 57.7 & 38.5 & 13.1 & 5.8 & 42.6 & 51.6 \\
\hline C. livia & 28.5 & 20.6 & 22.2 & 28.7 & 49.1 & 18.4 & 40.1 & 12.7 & 28.9 & 58.5 & 37.0 & 15.5 & 6.2 & 41.4 & 52.5 \\
\hline D. giganteus & 28.1 & 21.0 & 22.1 & 28.8 & 49.1 & 18.2 & 40.2 & 12.8 & 28.8 & 58.4 & 38.6 & 15.6 & 6.6 & 39.2 & 54.2 \\
\hline E. minor & 29.5 & 20.4 & 21.4 & 28.7 & 49.9 & 18.4 & 39.2 & 12.8 & 29.6 & 57.6 & 39.6 & 12.4 & 4.8 & 43.2 & 52.0 \\
\hline E. orientalis & 28.5 & 20.3 & 21.9 & 29.3 & 48.8 & 18.5 & 39.9 & 12.7 & 28.8 & 58.4 & 37.6 & 14.1 & 6.6 & 41.6 & 51.7 \\
\hline F. peregrinus & 29.5 & 20.7 & 21.4 & 28.4 & 50.2 & 18.4 & 39.5 & 12.8 & 29.4 & 57.9 & 40.7 & 14.3 & 5.3 & 39.7 & 55.0 \\
\hline G. californianus & 30.2 & 20.9 & 21.0 & 27.9 & 51.1 & 18.5 & 39.7 & 12.5 & 29.3 & 58.2 & 42.0 & 14.2 & 4.1 & 39.7 & 56.2 \\
\hline G. gallus & 28.8 & 20.8 & 21.7 & 28.6 & 49.6 & 18.1 & 39.9 & 12.7 & 29.3 & 58.0 & 38.0 & 13.5 & 5.7 & 42.8 & 51.5 \\
\hline G. stellata & 28.5 & 20.0 & 22.1 & 29.4 & 48.5 & 18.6 & 39.9 & 12.7 & 28.9 & 58.5 & 38.3 & 12.9 & 6.6 & 42.2 & 51.2 \\
\hline H. ater & 29.4 & 21.2 & 21.4 & 27.9 & 50.6 & 18.7 & 39.9 & 12.8 & 28.7 & 58.6 & 41.1 & 13.8 & 5.3 & 39.8 & 54.9 \\
\hline H. novaeseelandiae & 28.5 & 20.8 & 22.0 & 28.8 & 49.3 & 18.5 & 40.0 & 12.8 & 28.7 & 58.5 & 40.0 & 14.6 & 4.9 & 40.6 & 54.6 \\
\hline M. undulates & 29.4 & 20.8 & 20.8 & 28.9 & 50.2 & 18.6 & 39.4 & 12.4 & 29.6 & 58.0 & 41.6 & 12.5 & 3.6 & 42.3 & 54.1 \\
\hline M. novaehollandiae & 27.5 & 20.5 & 23.5 & 28.4 & 48.0 & 18.2 & 40.2 & 12.9 & 28.6 & 58.4 & 38.0 & 15.5 & 6.8 & 39.7 & 53.5 \\
\hline N. novaehollandiae & 28.9 & 19.8 & 21.5 & 29.8 & 48.7 & 18.3 & 39.0 & 12.7 & 30.1 & 57.3 & 40.0 & 12.4 & 6.3 & 41.4 & 52.4 \\
\hline P. azara & 28.3 & 20.8 & 21.7 & 29.2 & 49.1 & 18.2 & 39.8 & 12.7 & 29.3 & 58.0 & 31.7 & 11.3 & 6.4 & 50.6 & 43.0 \\
\hline P. rubber & 28.5 & 20.6 & 22.2 & 28.7 & 49.1 & 18.4 & 39.9 & 12.8 & 28.9 & 58.3 & 40.6 & 12.7 & 5.5 & 41.2 & 53.3 \\
\hline P. rubricauda & 27.7 & 19.8 & 22.2 & 30.2 & 47.5 & 18.1 & 39.5 & 13.0 & 29.4 & 57.6 & 35.6 & 11.5 & 8.6 & 44.2 & 47.1 \\
\hline R. americana & 27.0 & 21.0 & 22.5 & 29.4 & 48.0 & 18.0 & 40.0 & 12.9 & 29.0 & 58.0 & 33.0 & 15.8 & 8.2 & 42.9 & 48.8 \\
\hline R. jubatus & 28.7 & 20.8 & 22.4 & 28.1 & 49.5 & 18.5 & 39.8 & 12.6 & 29.1 & 58.3 & 38.4 & 17.8 & 5.9 & 37.9 & 56.2 \\
\hline S. camelus & 27.8 & 21.3 & 22.6 & 28.2 & 49.1 & 18.3 & 40.3 & 12.7 & 28.7 & 58.6 & 37.9 & 17.9 & 7.4 & 36.7 & 55.8 \\
\hline T. major & 29.5 & 22.7 & 20.7 & 27.0 & 52.2 & 18.3 & 40.1 & 12.8 & 28.8 & 58.4 & 37.3 & 21.8 & 5.2 & 35.7 & 59.1 \\
\hline T. melanophrys & 28.7 & 21.2 & 22.0 & 28.0 & 49.9 & 18.4 & 40.0 & 12.9 & 28.7 & 58.4 & 40.3 & 16.3 & 5.8 & 37.6 & 56.6 \\
\hline T. novaehollandiae & 29.4 & 20.4 & 21.2 & 28.9 & 49.8 & 18.6 & 39.5 & 12.6 & 29.3 & 58.1 & 42.9 & 10.5 & 4.6 & 42.1 & 53.4 \\
\hline T. viridis & 28.7 & 22.8 & 21.9 & 26.6 & 51.5 & 18.7 & 40.1 & 12.5 & 28.7 & 58.8 & 39.8 & 21.4 & 5.9 & 32.8 & 61.2 \\
\hline
\end{tabular}

There are four reading frame overlaps within the mitochondrial genome of C. livia (coxl and $t R N A^{\operatorname{Ser}(U C N)}$ share nine nucleotides; atp 8 and atp6 share 10 nucleotides; nad $4 L$ and nad4 share seven nucleotides; atp 6 and $\operatorname{cox} 3$ share one nucleotide). Other overlaps are shown in Table 3. 
Twelve genes (with the exception of nad6) of the 13 typical protein-coding genes (nad1-6 and 4L, cox1-3, atp6 and atp8, cob) are encoded on the heavy strand. All proteincoding genes initiate with ATG, except for coxl and nad5, which begins with GTG. Five types of stop codons are used by the coding genes, including TAA for nad3, cox2, atp 8, atp6, nad4L, and cob; AGA for nad 1 and nad5; TAG for nad6; AGG for coxl, and incomplete stop codon Tor TA- for cox3, nad2 and nad4, respectively. The use of an incomplete stop codon T, a common mechanism for stopping protein translations, was also observed in other avian species.

The pattern of codon usage in the C. livia mtDNA was also studied (Table 7). There are 3785 codons for all the 13 protein-coding genes, after stop codons are excluded. The most frequently used amino acid was Leu (17.89\%), followed by Thr $(9.30 \%)$, Ala (7.67\%), Ile (7.59\%), and Ser (7.43\%).

\begin{tabular}{|c|c|c|c|c|c|c|c|}
\hline $\begin{array}{l}\text { Amino } \\
\text { acid }\end{array}$ & Codon & Number & $\begin{array}{l}\text { Frequency } \\
(\%)\end{array}$ & $\begin{array}{l}\text { Amino } \\
\text { acid }\end{array}$ & Codon & Number & $\begin{array}{c}\text { Frequency } \\
(\%)\end{array}$ \\
\hline \multirow[t]{2}{*}{ Phe } & TTT & 47 & 1.24 & Tyr & TAT & 28 & 0.74 \\
\hline & TTC & 166 & 4.37 & & TAC & 86 & 2.27 \\
\hline \multirow[t]{6}{*}{ Leu } & TTA & 65 & 1.71 & Stop & TAA & 9 & 0.24 \\
\hline & TTG & 21 & 0.55 & & TAG & 1 & 0.03 \\
\hline & CTT & 76 & 2.00 & His & CAT & 22 & 0.58 \\
\hline & CTC & 187 & 4.93 & & CAC & 86 & 2.27 \\
\hline & CTA & 299 & 7.88 & Gln & CAA & 79 & 2.08 \\
\hline & CTG & 30 & 0.79 & & CAG & 13 & 0.34 \\
\hline \multirow[t]{2}{*}{ Ile } & ATT & 86 & 2.27 & Asn & AAT & 24 & 0.63 \\
\hline & ATC & 202 & 5.32 & & $\mathrm{AAC}$ & 105 & 2.77 \\
\hline \multirow[t]{2}{*}{ Met } & ATA & 132 & 3.48 & Lys & AAA & 74 & 1.95 \\
\hline & ATG & 40 & 1.05 & & $\mathrm{AAG}$ & 9 & 0.24 \\
\hline \multirow[t]{4}{*}{ Val } & GTT & 40 & 1.05 & Asp & GAT & 21 & 0.55 \\
\hline & GTC & 53 & 1.40 & & GAC & 43 & 1.13 \\
\hline & GTA & 56 & 1.48 & Glu & GAA & 79 & 2.08 \\
\hline & GTG & 22 & 0.58 & & GAG & 18 & 0.47 \\
\hline \multirow[t]{4}{*}{ Ser } & TCT & 34 & 0.90 & Cys & TGT & 7 & 0.18 \\
\hline & TCC & 107 & 2.82 & & TGC & 19 & 0.50 \\
\hline & TCA & 78 & 2.05 & Trp & TGA & 93 & 2.45 \\
\hline & TCG & 8 & 0.21 & & TGG & 12 & 0.32 \\
\hline \multirow[t]{4}{*}{ Pro } & $\mathrm{CCT}$ & 45 & 1.19 & Arg & CGT & 9 & 0.24 \\
\hline & CCC & 82 & 2.16 & & CGC & 16 & 0.42 \\
\hline & CCA & 93 & 2.45 & & CGA & 42 & 1.11 \\
\hline & $\mathrm{CCG}$ & 5 & 0.13 & & CGG & 6 & 0.16 \\
\hline \multirow[t]{4}{*}{ Thr } & $\mathrm{ACT}$ & 58 & 1.53 & Ser & AGT & 13 & 0.34 \\
\hline & ACC & 157 & 4.14 & & $\mathrm{AGC}$ & 42 & 1.11 \\
\hline & $\mathrm{ACA}$ & 130 & 3.42 & Stop & AGA & 2 & 0.05 \\
\hline & ACG & 8 & 0.21 & & $\mathrm{AGG}$ & 1 & 0.03 \\
\hline \multirow[t]{4}{*}{ Ala } & $\mathrm{GCT}$ & 50 & 1.32 & Gly & GGT & 27 & 0.71 \\
\hline & GCC & 139 & 3.66 & & GGC & 80 & 2.11 \\
\hline & GCA & 93 & 2.45 & & GGA & 80 & 2.11 \\
\hline & GCG & 9 & 0.24 & & GGG & 32 & 0.84 \\
\hline
\end{tabular}

\section{Non-coding regions}

The non-coding regions in the $C$. livia mitochondrial genome include a control region (D-loop) and a few spaces (Table 3). The control region (1657 bp) is located between $t R N A^{\text {Glu }}$ and $t R N A^{\text {Phe }}$ genes. The length of the control region of avian species varies between 1034 (Struthio camelus) and 3224 bp (Pteroglossus azara), ranging in AT content from 55.03 (B. canadensis) to $63.73 \%$ (E. minor and M. novaehollandiae; Table 4). 
Based on the distribution of the variable nucleotide positions and differential frequencies of the nucleotides, the mitochondrial control region is divided into three domains (Brown et al., 1986; Saccone et al., 1991; Randi and Lucchini, 1998). The nucleotide composition of the $C$. livia control region was $\mathrm{A}=30.84, \mathrm{~T}=27.40, \mathrm{C}=28.49$, and $\mathrm{G}=13.28 \%$ (Table 4), with a bias against $\mathrm{G}$, which is usual for the mtDNA sense strand of vertebrates (Wolstenholme, 1992). Domain I (ETAS, extended termination-associated sequences) contains part A (nt 1-146 in Figure 2) and part B (nt 147-398 in Figure 2). In part A, ETAS1 and ETAS2 are found at positions 71-126 and 108-146 nt, respectively, and overlapped one another by $19 \mathrm{bp}$, with 63.3 and $58.7 \%$ similarity to the consensus mammalian ETAS1 and ETAS2, respectively (Sbisa et al., 1997). In part B (nt 147-398), a CSB1-like block (5'-TAGAACTTAATGATACC TTAGACATA-3') has $63.0 \%$ similarity to the conserved sequence block (CSB1) in domain III (Figure 2). Four conserved sequence boxes in the central domain II (nt 399-897) were identified as boxes C, D, E, and F (Figure 2). In domain III (nt 898-1657), there is a poly (T) sequence (nt 1123-1131), which is located just a few nucleotides downstream from the putative CSB1 (nt 983-1007; Figure 2). Although the conserved blocks, such as ETAS1, ETAS2, CSB1, CSB1-like, and boxes $\mathrm{C}, \mathrm{D}, \mathrm{E}$, and $\mathrm{F}$, are readily identifiable in the C. livia control region, the typical origin of $\mathrm{H}$-strand replication $\left(\mathrm{O}_{\mathrm{H}}\right), \mathrm{CSB} 2$ and CSB3 could not be detected (Walberg and Clayton, 1981). The bidirectional light- and heavy-strand transcription promoters (LSP/HSP) (L'Abbé et al., 1991) are found in C. livia (Figure 2). Furthermore, there are 27 tandem repeats (CAAA) at the end of the C. livia control region.

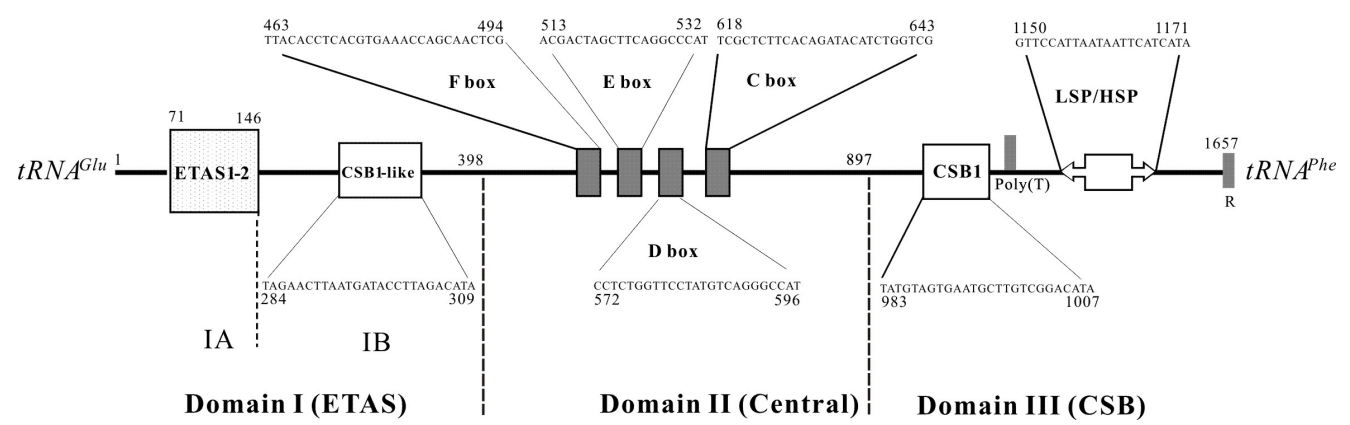

Figure 2. Schematic representation of the organization of the Columba livia control region. ETAS = extended termination-associated sequences; $\mathrm{F}$ through $\mathrm{C}$ boxes = conserved sequence boxes in the central domain; $\mathrm{CSB}=$ conserved sequence block; CSB-like $=$ a sequence similar to the $\mathrm{CSB}$; LSP $=$ light-strand transcription promoter; $\mathrm{HSP}=$ heavy-strand transcription promoter; $\mathrm{R}=$ tandem repeats.

\section{Ribosomal and transfer RNA genes}

The Rock pigeon mitochondrial genome has two rRNA subunits ( $s r R N A$ and $\operatorname{lr} R N A$ ), as in other vertebrates. The $\operatorname{sr} R N A$ gene is located between $t R N A^{\text {Phe }}$ and $t R N A^{\text {Val }}$ genes, and the $\operatorname{lr} R N A$ gene is located between $t R N A^{V a l}$ and $t R N A^{\operatorname{Leu}(U U R)}$ genes. The lengths of $\operatorname{sr} R N A$ and $\operatorname{lr} R N A$ are 973 and $1586 \mathrm{bp}$. The $\mathrm{A}+\mathrm{T}$ content of the $r R N A$ is $54.32 \%$, which is within the range observed for other avian species (Table 4).

Twenty-two tRNA genes were observed in the Rock pigeon mitochondrial genome. The tRNA genes are interspersed in the genome, ranging in size from $66\left(t R N A^{\operatorname{Ser}(A G Y)}\right)$ to 
$74\left(t R N A^{T r p}\right)$ nucleotides (Table 3). $t R N A^{C y s}$ and $t R N A^{\operatorname{Ser}(A G Y)}$, which were not found by the tRNAscan-SE, were identified by comparison with G. gallus counterparts. All tRNA gene sequences have the potential to fold into typical cloverleaf secondary structures (Figure 3 ). The DHU and T $\Psi \mathrm{C}$ arms contain two and five nucleotide pairs, respectively.
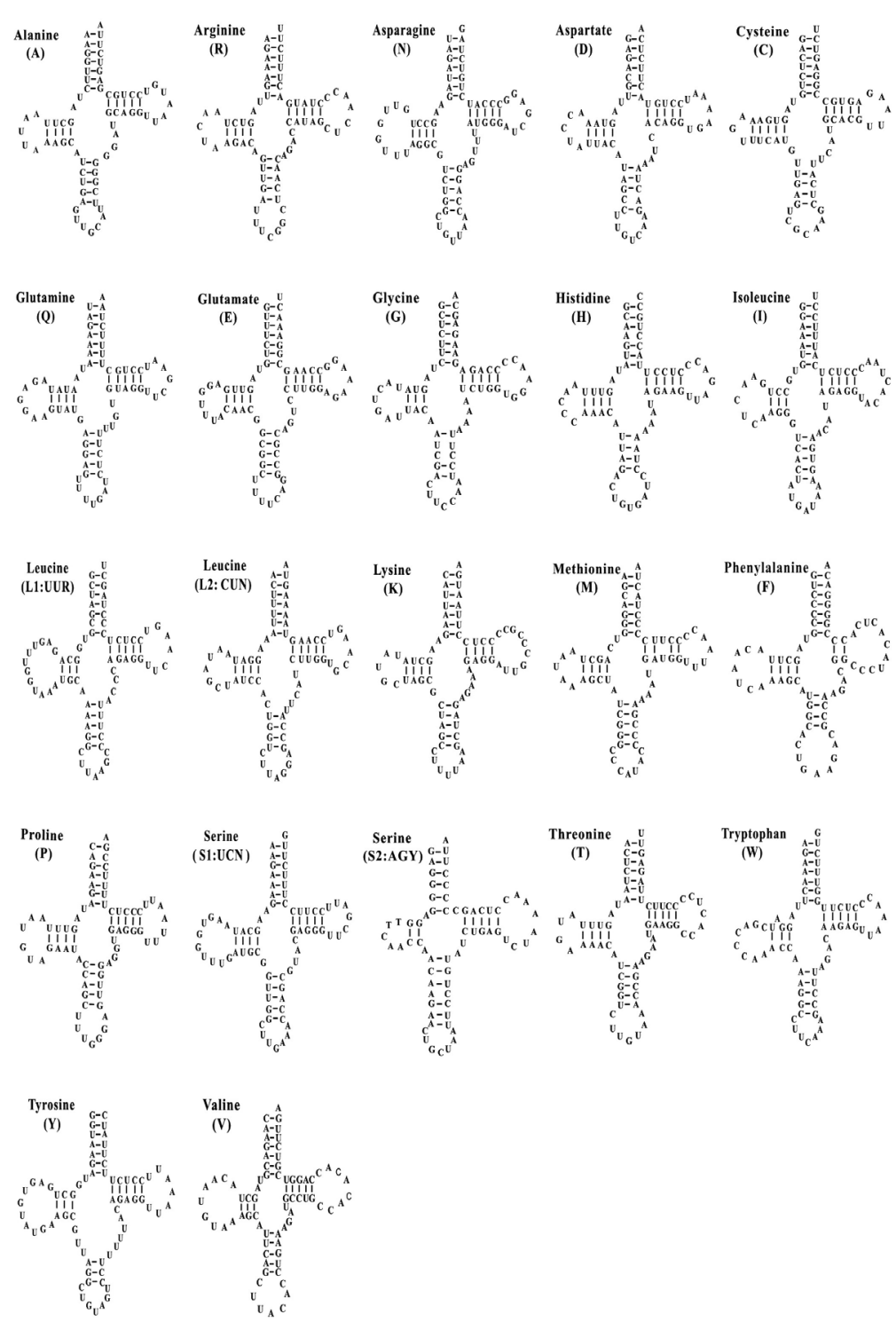

Figure 3. Inferred secondary structures of 22 tRNAs found in the Columba livia mitochondrial genome. 
This is the first complete nucleotide sequence described for the mitochondrial genome of the Rock pigeon. We also detailed the genome organization and codon usage of C. livia mitochondrial DNA. These results provide basic information for phylogenetic analyses among the birds, and especially Columbiformes species.

\section{ACKNOWLEDGMENTS}

Research supported by the National Natural Science Foundation of China (\#30870172), the Key Program of Natural Science Foundation of the Anhui Higher Education Institutions (\#KJ2008A13ZC), the Natural Science Foundation of Anhui Normal University (\#2008xzx14), the Key Lab of Biotic Environment and Ecology Safety in Anhui Province, and the Program for Innovative Research Team in Anhui Normal University.

\section{REFERENCES}

Boore JL (1999). Animal mitochondrial genomes. Nucleic Acids Res. 27: 1767-1780.

Brown GG, Gadaleta G, Pepe G, Saccone C, et al. (1986). Structural conservation and variation in the D-loop-containing region of vertebrate mitochondrial DNA. J. Mol. Biol. 192: 503-511.

Cooper A, Lalueza-Fox C, Anderson S, Rambaut A, et al. (2001). Complete mitochondrial genome sequences of two extinct moas clarify ratite evolution. Nature 409: 704-707.

Gibb GC, Kardailsky O, Kimball RT, Braun EL, et al. (2007). Mitochondrial genomes and avian phylogeny: complex characters and resolvability without explosive radiations. Mol. Biol. Evol. 24: 269-280.

Haddrath O and Baker AJ (2001). Complete mitochondrial DNA genome sequences of extinct birds: ratite phylogenetics and the vicariance biogeography hypothesis. Proc. Biol. Sci. 268: 939-945.

Hall AT (1999). BioEdit: a user-friendly biological sequence alignment editor and analysis program for Windows 95/98/ NT. Nucleic Acids Symp. Ser. 41: 95-98.

Harlid A, Janke A and Arnason U (1998). The complete mitochondrial genome of Rhea americana and early avian divergences. J. Mol. Evol. 46: 669-679.

Harrison GL, McLenachan PA, Phillips MJ, Slack KE, et al. (2004). Four new avian mitochondrial genomes help get to basic evolutionary questions in the late cretaceous. Mol. Biol. Evol. 21: 974-983.

Hazkani-Covo E, Zeller RM and Martin W (2010). Molecular poltergeists: mitochondrial DNA copies (numts) in sequenced nuclear genomes. PLoS Genet. 6: e1000834.

Howard R and Moore A (2003). The Howard and Moore Complete Checklist of the Birds of the World. 3rd edn. Christopher Helm, London.

L'Abbé D, Duhaime JF, Lang BF and Morais R (1991). The transcription of DNA in chicken mitochondria initiates from one major bidirectional promoter. J. Biol. Chem. 266: 10844-10850.

Larkin MA, Blackshields G, Brown NP, Chenna R, et al. (2007). Clustal W and Clustal X version 2.0. Bioinformatics 23: 2947-2948.

Livezey BC and Zusi RL (2007). Higher-order phylogeny of modern birds (Theropoda, Aves: Neornithes) based on comparative anatomy. II. Analysis and discussion. Zool. J. Linn. Soc. 149: 1-95.

Lohse M, Drechsel O and Bock R (2007). OrganellarGenomeDRAW (OGDRAW): a tool for the easy generation of highquality custom graphical maps of plastid and mitochondrial genomes. Curr. Genet. 52: 267-274.

Lowe TM and Eddy SR (1997). tRNAscan-SE: a program for improved detection of transfer RNA genes in genomic sequence. Nucleic Acids Res. 25: 955-964.

Mindell DP, Sorenson MD and Dimcheff DE (1998). Multiple independent origins of mitochondrial gene order in birds. Proc. Natl. Acad. Sci. U. S. A. 95: 10693-10697.

Moore WS (1995). Inferring phylogenies from mtDNA variation: mitochondrial-gene trees versus nuclear-gene trees. Evolution 49: 718-726.

Morgan-Richards M, Trewick SA, Bartosch-Harlid A, Kardailsky O, et al. (2008). Bird evolution: testing the Metaves clade with six new mitochondrial genomes. BMC Evol. Biol. 8: 20.

Nishibori M, Hayashi T, Tsudzuki M, Yamamoto Y, et al. (2001). Complete sequence of the Japanese quail (Coturnix japonica) mitochondrial genome and its genetic relationship with related species. Anim. Genet. 32: 380-385. 
Nishibori M, Shimogiri T, Hayashi T and Yasue H (2005). Molecular evidence for hybridization of species in the genus Gallus except for Gallus varius. Anim Genet. 36: 367-375.

Paton T, Haddrath O and Baker AJ (2002). Complete mitochondrial DNA genome sequences show that modern birds are not descended from transitional shorebirds. Proc. Biol. Sci. 269: 839-846.

Pereira SL, Johnson KP, Clayton DH and Baker AJ (2007). Mitochondrial and nuclear DNA sequences support a Cretaceous origin of Columbiformes and a dispersal-driven radiation in the Paleocene. Syst. Biol. 56: 656-672.

Perna NT and Kocher TD (1995). Patterns of nucleotide composition at fourfold degenerate sites of animal mitochondrial genomes. J. Mol. Evol. 41: 353-358.

Pratt RC, Gibb GC, Morgan-Richards M, Phillips MJ, et al. (2009). Toward resolving deep neoaves phylogeny: data, signal enhancement, and priors. Mol. Biol. Evol. 26: 313-326.

Randi E and Lucchini V (1998). Organization and evolution of the mitochondrial DNA control region in the avian genus Alectoris. J. Mol. Evol. 47: 449-462.

Rokas A, Williams BL, King N and Carroll SB (2003). Genome-scale approaches to resolving incongruence in molecular phylogenies. Nature 425: 798-804.

Saccone C, Pesole G and Sbisa E (1991). The main regulatory region of mammalian mitochondrial DNA: structurefunction model and evolutionary pattern. J. Mol. Evol. 33: 83-91.

Sambrook J and Russell DW (2001). Molecular Cloning: A Laboratory Manual. 3rd edn. Cold Spring Harbor Laboratory Press, New York.

San Mauro D, Garcia-Paris M and Zardoya R (2004). Phylogenetic relationships of discoglossid frogs (Amphibia: Anura: Discoglossidae) based on complete mitochondrial genomes and nuclear genes. Gene 343: 357-366.

Sbisa E, Tanzariello F, Reyes A, Pesole G, et al. (1997). Mammalian mitochondrial D-loop region structural analysis: identification of new conserved sequences and their functional and evolutionary implications. Gene 205: 125-140.

Shadel GS and Clayton DA (1997). Mitochondrial DNA maintenance in vertebrates. Annu. Rev. Biochem. 66: 409-435.

Shen X, Tian M, Liu Z, Cheng H, et al. (2009). Complete mitochondrial genome of the sea cucumber Apostichopus japonicus (Echinodermata: Holothuroidea): the first representative from the subclass Aspidochirotacea with the echinoderm ground pattern. Gene 439: 79-86.

Slack KE, Janke A, Penny D and Arnason U (2003). Two new avian mitochondrial genomes (penguin and goose) and a summary of bird and reptile mitogenomic features. Gene 302: 43-52.

Slack KE, Jones CM, Ando T, Harrison GL, et al. (2006). Early penguin fossils, plus mitochondrial genomes, calibrate avian evolution. Mol. Biol. Evol. 23: 1144-1155.

Slack KE, Delsuc F, McLenachan PA, Arnason U, et al. (2007). Resolving the root of the avian mitogenomic tree by breaking up long branches. Mol. Phylogenet. Evol. 42: 1-13.

Walberg MW and Clayton DA (1981). Sequence and properties of the human KB cell and mouse L cell D-loop regions of mitochondrial DNA. Nucleic Acids Res. 9: 5411-5421.

Wang C, Chen Q, Lu G, Xu J, et al. (2008). Complete mitochondrial genome of the grass carp (Ctenopharyngodon idella, Teleostei): insight into its phylogenic position within Cyprinidae. Gene 424: 96-101.

Wolstenholme DR (1992). Animal mitochondrial DNA: structure and evolution. Int. Rev. Cytol. 141: 173-216.

Wyman SK, Jansen RK and Boore JL (2004). Automatic annotation of organellar genomes with DOGMA. Bioinformatics 20: 3252-3255.

Xia X and Xie Z (2001). DAMBE: software package for data analysis in molecular biology and evolution. J. Hered. 92: 371-373. 